Meta

Journal des traducteurs

Translators' Journal

\title{
Experiences with Metal at the Belgian Ministry of the Interior
}

\section{F. Deprez, G. Adriaens, B. Depoortere et G. de Braekeleer}

Volume 39, numéro 1, mars 1994

La traduction et l'interprétation dans la Belgique multilingue

URI : https://id.erudit.org/iderudit/002540ar

DOI : https://doi.org/10.7202/002540ar

Aller au sommaire du numéro

Éditeur(s)

Les Presses de l'Université de Montréal

ISSN

0026-0452 (imprimé)

1492-1421 (numérique)

Découvrir la revue

Citer cet article

Deprez, F., Adriaens, G., Depoortere, B. \& de Braekeleer, G. (1994). Experiences with Metal at the Belgian Ministry of the Interior. Meta, 39(1), 206-212.

https://doi.org/10.7202/002540ar

\section{Résumé de l'article}

Cet article décrit les expériences effectués sur le système METAL - système de traduction de textes techniques - au Ministère de l'intérieur de la Belgique en collaboration avec Siemens Nixdorf's. La première partie explique les mises au point apportés au système lors du projet pilot. La deuxième partie démontre une application réelle du système METAL. 


\title{
EXPERIENCES WITH METAL AT THE BELGIAN MINISTRY OF THE INTERIOR
}

\author{
F. DEPREZ ${ }^{a}$, G. ADRIAENS ${ }^{a}, b$, B. DEPOORTERE AND G. DE BRAEKELEER \\ a Siemens Nixdorf Centre software Liège, Liège; \\ bUniversity of Leuven Centre for Computational Linguistics, Leuven, Belgique
}

\begin{abstract}
Résumé
Cet article décrit les expériences effectués sur le système METAL - système de traduction de textes techniques - au Ministère de l'intérieur de la Belgique en collaboration avec siemens Nixdorf's. La première partie explique les mises au point apportés au système lors du projet pilot. La deuxième partie démontre une application réelle du système METAL.
\end{abstract}

\begin{abstract}
In this paper we describe our experiences with Siemens Nixdorf's METAL system at the Belgian Ministry of the Interior. In the first part (sections 1,2,3 and 4) we report on the tuning phase during the pilot project. The second part (section 5) describes a prototypical real-life METAL translation session.
\end{abstract}

\section{GENERAL OVERVIEW OF THE PILOT PROJECT}

In October 1989 collaboration started between the Belgian Ministry of the Interior and Siemens-Nixdorf: two to three officials and two Siemens-Nixdorf employees tuned the existing METAL system - conceived initially as a translation system for technical texts - to the needs of the Belgian administration. The language pairs concerned were Dutch to French and French to Dutch ${ }^{1}$.

The tuning phase included enlargement of the dictionaries, massive testing and debugging, and the creation of an appropriate user interface. It turned out to be very important that translators were involved in the phase of lexical coding: this changed their initial scepticism into identification with the system. Participation of the translators in the test and debugging phase led to a correct estimate of the system's possibilities and limitations. The presence of developers at the users' site ensured well-founded extensions of the grammar modules and avoided getting bogged down in theoretical linguistic discussions without any relevance for the improvement of translation quality.

An important parameter for the success of a translation system is its integration in the text environment. As the text processor most commonly used in the Belgian administration is WordPerfect, we developed a converter to be able to handle texts in this format.

The METAL installation consists of a Symbolics ${ }^{2}$ (Lisp machine, workstation) responsible for the translations, a SNI MX300 (Unix machine, 4 terminals) running the interface for translators and a scanner connected to a SNI PCD-2 (Dos PC).

\section{DICTIONARIES}

Within the METAL system, translators can introduce their own lexicon.

METAL allows new lexical entries to be introduced via 'Intercoder' (a user-friendly tool on Symbolics, especially for inexperienced users) or via 'Expert coding tools' (tools on Symbolics, more complicated than the Intercoder, but faster). However, none of these instruments are particularly suited for massive lexical coding. To introduce about 70.000 
Dutch-French or French-Dutch transfer entries and their corresponding monolingual entries, we needed a third way of coding, viz. mass coding tools.

\section{Mass coding tools}

With intercoder and expert coding tools, one generally concentrates on all aspects of a single entry at any one time (monolingual features, transfer information, etc.). Mass coding implies a different focus: all (or one category of) entries at any one stage are concerned (first transfer coding of all entries, then mono-coding for entries of one category, etc.).

The mass coding tools were developed on the SNI MX300 in order to allow several translators to code simultaneously, which is impossible with the intercoder and expert coding tools on Symbolics.

As it was hard to foresee how well the existing functionality (the possibility of treating collocations, translations in context, etc.) for transfer entries would cope with the particularities of administrative and legal terminology, we could not let the translators code only what the system was capable of: this might have led to an irresponsible restriction on the dictionaries. On the other hand, we could not implement new functionality before knowing the nature and frequency of phenomena that had not yet been covered. We therefore provided the possibility of coding everything the translator wanted in an implementation-independent way, trying as far as possible, however, to avoid reviewing lexical entries during conversion to the implementation-dependent format.

During monolingual coding we focused on one feature at any one time for all entries of a given category: first code the morphological information of all nouns, then code the semantic type, etc. This strategy guaranteed fast, consistent coding.

\section{Functionality for administrative and legal vocabulary}

About $40 \%$ of all entries are collocations, of which less than $20 \%$ can be translated more or less literally. Adequate and sometimes more economic coding strategies had to be developed, especially for complex nouns and verbs.

For analysing French we had already developed a strategy for complex noun structures of the type 'noun + invariable part' (e.g. Ministère de l'Intérieur): a grammar rule builds a complex noun combining the nominal head (Ministère) and the nominal adjunct (de l'Intérieur), both coded in the monolingual dictionary. This strategy was not implemented for Dutch - the phenomenon is almost absent in the general vocabulary; we were finally forced to adopt it, however, because we had to deal with more than 3.000 noun-adjunct combinations in the administrative domain.

The most economic solution to translating combinations of noun and adjective, present participle or past participle was to provide functionality in the transfer lexicon: the test part checks the presence of an adjectival modifier, the action part contains instructions needed for the appropriate translation. In the entry below ${ }^{3}$, the translation of lettre recommandée is forced into registered letter, avoiding the literal translation recommended character.

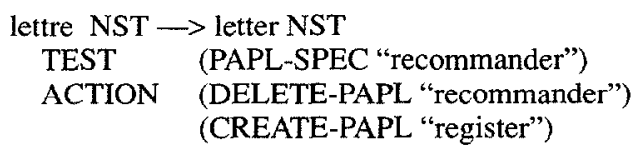

Similar functionality was needed for contextual verb transfer. In the following expressions, the six French verbs are the translation of the same Dutch verb opheffen (raize, lift): 
lever la séance

éteindre une pension

rabattre un défaut

rétracter un arrêt.

rapporter une loi

révoquer la faillite

The coding of such entries can be illustrated by the French expression prendre des renseignements and its translation in English to make inquiries:

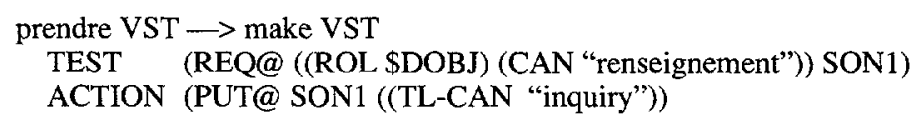

\section{TESTING AND DEBUGGING}

The aim of this phase was to debug the dictionaries and grammar modules and to detect any deterioration of translation quality due to the new dictionaries. The Sisyphus toolkit ${ }^{4}$ was used to test and evaluate two sets of test corpora.

The first consisted of artificially constructed translation units (about 20.000 for each translation direction) and was meant to test the quality and consistency of the new dictionaries as well as the robustness of the additional lexical functionality. The test corpora for nouns and adjectives were derived automatically or semi-automatically from the transfer dictionaries created with the mass coding tools. Test corpora for verbs or verbal expressions, however, had to be created manually (one translation unit for each translation).

The second set of test corpora contained real-world text material (about 500 pages for each translation direction): this led to the detection of all kinds of translation errors and, as a consequence, to the fine tuning of the dictionaries and grammar modules. One particular problem in this respect was homography due to larger dictionaries that sometimes gave rise to wrong interpretations. It is indeed easier to analyse Elle est tombée if tombée is coded only as a past participle and not as a noun.

During the testing of real-world text material, we were also confronted with the major problem of the length of translation units. On the one hand, translation quality and speed within METAL tend to decrease considerably for sentences longer than 20 words. On the other, the average administrative text is very complex as far as sentence length is concerned: about $76 \%$ of the text volume consists of sentences of more than 20 words (against 30\% for the average technical text). The solution to this problem is the manually splitting of long translation units during pre-editing (see below).

The test corpora were treated as follows. METAL first translated the corpus, and the translator evaluated the results, assigning to each translation unit a quality label (correct, understandable or wrong). After lexical and grammatical debugging based on all incorrect translation units, the entire corpus was translated and evaluated a second time. The average translation quality ${ }^{5}$ assigned by the translators to the second translation of lexical corpora was about $90 \%$ and $80 \%$ for real-world corpora. From these percentages onwards, METAL proved to be productive for new text material.

\section{ADAPTATIONS TO THE INTERFACE}

As deadlines for translators are tight, we had to implement the possibility of dividing the input text automatically into different parts according to certain parameters. As a consequence, several translators can work simultaneously on the same text or translation of one part can begin while other parts are still being pre-edited: 


\begin{tabular}{|c|c|c|c|c|}
\hline & \multicolumn{4}{|c|}{ input text } \\
\hline & 1 & 1 & i & 1 \\
\hline \multirow[t]{2}{*}{ pre-editing } & part-01 & part-02 & part-03 & $\ldots$ \\
\hline & i & 1 & 1 & $i$ \\
\hline \multirow[t]{2}{*}{ translation } & part-01 & part-02 & part-03 & $\ldots$ \\
\hline & i & I & i & $i$ \\
\hline \multirow[t]{2}{*}{ post-editing } & part-01 & part-02 & part-03 & $\ldots$ \\
\hline & 1 & 1 & 1 & 1 \\
\hline
\end{tabular}

The preanalysis program detects words in the input text that are unknown to the system (UNKs). Because of the short deadlines, we abandoned the idea of a preanalysis on Symbolics based on morphological analysis and implemented fast preanalysis on MX300 based on full-form dictionaries.

All words in the input text are matched with a full-form dictionary. Missing words are considered to be unknown and collected into a file that gets translated on Symbolics. This translation may reveal why a word is unknown and what action should be taken. If the UNK is a proper name that should not be translated (names of persons, machines, etc), it might be interesting to protect it in the appropriate way into the input text (see below); if it is a word that is simply not yet in the METAL dictionaries it should be coded, at least if the UNK does not contain spelling mistakes, in which case it should be corrected in the input text.

Because of the frequency of complex noun structures in the administrative domain, we introduced appropriate preanalysis for French. Although preanalysis for single nouns is more reliable than preanalysis for multiword nouns, we detect up to $60 \%$ of them. To do this, we isolate all occurrences of noun de noun, noun de la noun, etc. and translate them if they are missing in the full-form dictionary in order to check whether the compositional translation is acceptable or not.

As a solution to the problem of long translation units, the translator is asked to split them up using the \#-character. Place holders may be introduced in order to keep sentences grammatically correct: ' $\mathrm{s} 1$ ' replaces a noun phrase with semantic type '+ human', 's0' a noun phrase with semantic type '- human', 'aa' replaces an adverbial complement, etc. With this technique, antecedents, subjects, direct objects and adverbial or prepositional complements can be split off in order to create shorter translation units. So, the sentence Dans une réunion qui a duré trois heures, le directeur de la division a accepté les propositions des employés can be split as below:

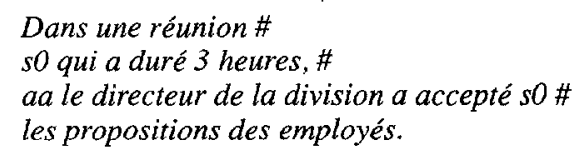

Strings that should not be translated (certain proper names, etc.) can be protected automatically using the METAL Pattern Matcher (MPM). The instruction below avoids the inappropriate translation of $M$. Le Roi, directeur into the Dutch equivalent of ' $M$. The King, director'.

$$
\text { REPLACE "M. Le Roi” } \rightarrow \text { “ }\{\text { M. Le Roi }\} "
$$

In order to be able to exploit the MPM's functionality to the full, we implemented an MPM instructions generator: every string that may need to be protected is presented in 
an instruction of the form REPLACE "string" $\rightarrow$ "\{string\}" to the translator, who can accept, adapt or refuse it.

As it seemed useful to the translators and developers to be able to measure the productivity of the METAL system, we integrated the possibility of logging the most important steps during pre-editing and post-editing. This feature allows us to describe a translation session in the following paragraph.

\section{A METAL TRANSLATION SESSION}

In what follows, we describe how 2 translators translated a text of 50 pages (one page being 250 words) using the METAL system in more or less 24 working hours. As the translators worked simultaneously most of the time, the translation was ready after 14 working hours.

TIME TRANSLATOR $1: 00.00$

TIME TRANSLATOR $2: 00.00$

The converter scans the input WP document and creates a document in MDIF format (METAL Document Interchange Format) containing the text and lay-out information such as fonts, tabulators, headers and footers, etc.

TIME TRANSLATOR $1: 00.05$

TIME TRANSLATOR $2: 00.00$

The text is split up into 5 parts, in order to allow parallel treatment.

TIME TRANSLATOR $1: 00.10$

TIME TRANSLATOR $2: 00,00$

Preanalysis for single and/or complex words is started. This process runs in batch mode and takes less than 1 minute per page ( 30 minutes for 50 pages).

The MPM-proposals are checked and completed if necessary (15 minutes for 50 pages).

TIME TRANSLATOR $1: 00.25$

TIME TRANSLATOR $2: 00.00$

The first part of the text is deformatted. Layout information (tables, fonts, sentence boundaries, etc.) is extracted and stored in appropriate files. The linguistic information (pure text) is passed through the METAL pattern matcher. The result is presented to translator 1 who can prepare it manually by splitting up longer translation units, correcting spelling mistakes, etc. per page.

The process of deformatting and manual preparation takes more or less 5 minutes

TIME TRANSLATOR $1: 01.15$

TIME TRANSLATOR $2: 00.00$

As preanalysis is finished, translator 1 can start coding the unknown words.

TIME TRANSLATOR $1: 02.25$

TIME TRANSLATOR $2: 00.00$

While translator 1 is coding unknown words, translator 2 deformats and prepares part 3.

TIME TRANSLATOR $1: 03.15$

TIME TRANSLATOR $2: 00.50$

As all unknown words are coded, the first part of the text can be sent to the Symbolics machine for translation. This process runs in batch mode and takes about 5 minutes per page. 
Meanwhile, the translators deformat and prepare parts 2 and 4.

TIME TRANSLATOR $1: 04.10$

TIME TRANSLATOR $2: 01.40$

Part 3 is sent to the Symbolics machine for translation. Translator 2 deformats and prepares part 5.

As the raw translation of the first part is finished, translator 1 can start revision and reformatting.

Revision is carried out in the METAL editor on an interlinear version of the text where translation units of source and target language alternate. The METAL pattern matcher is used to get rid of place holders introduced during pre-editing and to correct frequent system errors.

Reformatting produces a document in MDIF format based on the revised translation and the files created during deformatting.

Revision and reformatting take more or less 20 minutes per page.

TIME TRANSLATOR $1: 05.00$

TIME TRANSLATOR $2: 02.30$

Parts 2, 4 and 5 are sent to the Symbolics machine for translation.

Translator 2 starts revising part 3 .

TIME TRANSLATOR $1: 07.30$

TIME TRANSLATOR $2: 05.00$

Revision and reformatting of part 1 is finished. Revision of part 2 starts.

TIME TRANSLATOR $1: 14.10$

TIME TRANSLATOR $2: 09.30$

Revision and reformatting of all parts are completed. The result is put in one file that is reconverted into WP format.

TIME TRANSLATOR $1: 14.15$

TIME TRANSLATOR $2: 09.30$

\section{CONCLUSION}

The experiences with Metal at the Belgian Ministry of the Interior (where the system is still being used productively) have taught us a number of interesting things. First, the introduction of the system in a new text environment (here: administration) requires massive lexicon tuning before the system can be used productively. Second, it is essential for smooth introduction and acceptance of a complex MT system like Metal that the translators be involved right from the start. And finally, the system as a whole proves to bring about an increase in translation productivity af about $100 \%$ (i.e. translators can handle twice as many pages with Metal than they handle without the system). Even though we have a long way to go, such results show that machine translation is a viable technology in a world with an ever increasing volume of material to be translated.

\footnotetext{
Notes

1. For the sake of clarity Dutch examples will be replaced by English counterparts.

2. In new installations, a SUN workstation will replace the Symbolics machine.

3. The entry is slightly simplified.

4. See Adriaens et al. for a detailed description.

5. See Adriaens et al. for the calculaltion of translation quality.
} 


\section{REFERENCES}

ADRIAENS, G. and H. CAEYERS (1990): "Het automatisch-vertaalsysteem METAL: van onderzoek tot commercieel produkt", Ingénieur \& Industrie, Dec. 1990, pp. 281-288.

ADRIAENS, G. et al. (1993): "Sisyphus: a Toolkit for MT Testing and Evaluating", Internal METAL documentation, Siemens-Nixdorf Liège, Belgium.

FONTENELLE, T. et al. (1993), "L'unité lexicale dans le système de traduction assistée par ordinateur METAL", P. Bouillon et A. Clas (dir.), La traductique Presse de l'Université de Montréal et AUPELF/UREF.

CARCIA X. and X. RODELLAR (1991): "ODIF/MDIF Convertors", Esprit Translator's Workbench Report.

SLOCUM, J. and W. S. BENNETT (1985): "An Evaluation of Metal: the LRC Machine Translation System", Working paper LRC-85-2, The University of Austin, Texas. Also presented as a paper at the 2nd EACL, Geneva 1985 .

THURMAIR, G. (1990): "Complex Lexical Transfer in METAL", Third International Conference on Theoretical and Methodological Issues in Machine Translation of Natural Languages. Austin, Texas, pp. 91-107.

THURMAIR, G. (1992): "METAL: Computer Integrated Translation", Internal METAL documentation, Siemens-Nixdorf Munich, Germany. 